\author{
Arielle VanderSchans \\ University of Western Ontario, London, Ontario, Canada
}

\title{
A Pilot Study Examining the Information Seeking of Fiction Writers
}

\begin{abstract}
Résumé:
This paper explores the information-seeking behaviours of fiction writers through a pilot study using an online survey. The information-seeking behaviour of fiction writers has been understudied, with the focus in Library and Information Science research falling predominantly on readership and publishing. This study represents an early step in exploring creativity and serendipity's role in the information-seeking habits of storytellers.
\end{abstract}

\section{Introduction}

This paper explores the information-seeking behaviour of fiction writers through a pilot study using an online survey. Library and Information Science (LIS) has a long history of studying publishers and readers but there is a surprising absence of research on writers. Within LIS, information-seeking is a well-established focus, but there is little research done on the writing process of storytellers in relation to their information-seeking behaviour. This sentiment is echoed across the scarce literature surrounding the research habits and information-seeking behaviour of fiction writers as the creative process of writer's and their information-seeking is not yet well researched (Desrcohers \& Pecoskie 2015, Holappa 2017). This results in, unfortunately, a significant gap about information-seeking during the writing stage. What information there is criticized as being "testimonial rather than empirical [... and though] is fascinating, often beautiful and eloquent, it is not scientific, but rather partisan and often published in mainstream media" (Desrochers \& Pecoskie 2015, p. 312). Researchers have slowly begun to look at small subgroups of fiction writers' information-seeking behavior, focusing on specific genres or age groups. Holappa (2017) has studied science fiction and fantasy writers and Smith (2005) looked at the authors of children's literature and young adult novels. This gap of research on the information-seeking behavior of writers needs to be addressed, as they pose a valuable opportunity to bring three important areas of research together. Fiction writers can act as a bridge between the research done on the creative process (in fields such as psychology, sociology, and others), the research done on serendipity, and the research on information-seeking in LIS. This pilot study sought to explore that gap and provide insight into future research as this is part of on-going work for my dissertation.

\section{Methods}

This pilot study was conducted through a survey administered to an online writing community. This survey consisted of 32 questions which sought to answer the following five research questions: 
1. What is the individual's identity as a writer?

2. What is the nature of writer's information seeking?

3. When does research come into the writer's writing process?

4. What resources are used by writers?

5. How do writers define failure in their information seeking process?

Along with the five research questions two hypotheses were proposed. These were created based of general assumptions and stereotypes in the writing community. This first hypothesis is: there is no relationship between the genre writers write in and the likelihood they give up on a writing project. The second hypothesis is: there is no relationship between whether a writer plots or doesn't, and the amount of time they spend researching.

The target population for this pilot study was amateur (defined as writers who have never published) fiction writers in North America. Participants were gathered using the nonprobabilistic sampling method of self-selection. The survey was sent out as a web-based survey and writers were asked to participate if they would like. Those who participated could also share the survey to their writing friends, utilizing the snowballing technique to gather more participants. To allow the survey to be seen it was shared with an online writing group, called "Bunch of Lunatics", and they were invited to take the survey. The group has 30-40 members, with about 20 active members. Within this group there are people who identify as male, female, and along the LGBTQ spectrum. This group consists of members ranging from early 20 's to early 60's in terms of age. There is a wide variety of genres being written by this group (fantasy, science-fiction, romance, historical, etc.), and the writers in this group are all at various stages of the writing process. While this sample is unlikely to be representative of the writer population, it is important to note that this study is a pilot study and that this survey is designed as a starting point for future research. 33 participants took part in the survey. Once the data was collected it was analyzed quantitatively in SPSS using the chi square test.

\section{Results}

The data analysis portion is broken down into the five research questions, exploring each variable related to the question, before finally testing the two proposed hypotheses. As mentioned before the five areas covered were: an individual's identity as a writer, the nature of a writer's information-seeking, the research in a writer's process, the resources used by a writer, and how writer's regarded failure in their information-seeking process. The first hypothesis tested for a relationship between the genre in which writers write, and the likelihood they give up on the writing project. The assumption was that certain genres may require more informationseeking and result in more struggles which would perhaps cause the writer to be more likely to give up on their writing project. The data showed that there was less expressed frustration and less giving up than anticipated by the researcher. The data collected was also to sparsely spread across the cells to properly test. The second hypothesis tested for a relationship between whether the writer plots or not before writing, and the amount of time they spend researching. The assumption was that writers who plot before writing spend more time researching than those who jump in and begin writing without plotting. As with the first hypothesis, there is not enough data to properly test this hypothesis. 


\section{Conclusions}

Despite the data sample being too small to draw any conclusions or perform any tests with validity, there were some surprises from this pilot study. Some assumptions that were held were challenged with by data. One of these was the lack of frustration and discouragement writers felt during information-seeking, and the second was how divided writers are on whether they plot before writing or not. Collecting more data to get more responses in the genre categories would allow for some interesting tests, such as comparing the genre writer's write in to the importance they feel research is to their work, rather than just how much of their time is spent researching. One could also explore further the feelings of frustrations and if there is a relationship between them and the genre the writer's write in. Further research questions could also explore more feelings and instances of serendipity, rather than just focusing on frustration and discouragement. Unfortunately, this data sample is too small to truly gain any insight into writers' informationseeking habits, but it has raised more questions and provided direction for further research to be done to explore the individual writer's creative process and their information seeking-habits, along with the notion of serendipity and creativity. While there is a benefit to survey data when a group is as diverse as writers are (both in their identity and creative methods) arguably more fruitful data could be obtained through qualitative research as opposed to quantitative research like this survey.

\section{Future Research}

Going forward I plan to continue to explore the notions of creativity and serendipity within information-seeking behaviour, focusing on fiction writers. This is intended to be a qualitative study, with an examination of interviews that will be coded using a custom designed tool grounded in the components of creativity and serendipity. This research is part of my $\mathrm{PhD}$ research project.

\section{Reference List:}

Desrochers, Nadine \& Pecoskie, Jen. (2015). Studying a boundary-defying group: An analytical review of the literature surrounding the information habits of writers. Library \& Information Science Research, Vol 37 Iss. 4 pp. 311-322

Holappa, Harri (2017). The Information-Seeking Behaviour of Science Fiction and Fantasy Writers. Master's Thesis. University of Oulu, Finland.

Smith, Jennifer. 2015. “The Information Behaviour of Authors Children's and Young Adult Literature", Aberystwyth University. Wales, UK. pg. 151-198 